\title{
Refractory Celiac Disease Successfully Treated With Azathioprine
}

\author{
Umair Iqbal $^{\text {a, c }}$, Ahmad Chaudhary ${ }^{\mathrm{a}}$, Muhammad Arsalan Karim ${ }^{\mathrm{b}}$, \\ Hafsa Anwar ${ }^{\mathrm{b}}$, Nancy Merrell ${ }^{\mathrm{a}}$
}

\begin{abstract}
Refractory celiac disease (CD) is a clinical diagnosis defined by the persistence of signs/symptoms, laboratory abnormalities or villous atrophy typical of $\mathrm{CD}$ despite strict adherence to a gluten-free diet for at least $6-12$ months. It should be suspected when patients with CD fail to respond primarily or secondarily to a gluten-free diet, especially if there is significant weight loss. Differentiation between types is important both for management and predicting prognosis. Type I can be managed with mild immunosuppression with nutritional support. Type II requires strong immunosuppression like azathioprine. Recently, autologous stem cell transplantation has also been used to treat type II.
\end{abstract}

Keywords: Refractory celiac disease; Non-responsive CD; Azathioprine

\section{Introduction}

Celiac disease (CD) is a T-cell mediated disorder characterized by mucosal inflammation and villous atrophy of the small intestine with gluten-free diet being the single most important measure for the treatment [1]. About $0.7-1.5 \%$ of the people with CD develop refractory celiac disease (RCD) [2-4]. Prevalence of RCD is quite rare estimated to be approximately 20,000 patients in the USA [3] with women two to three times more likely to be affected than men [5]. Patients with RCD are usually older than 50 years [3] with average age at diagnosis 53 years compared to the average age at diagnosis for CD 44 years [4].

RCD is subdivided into two types based on mucosal Tcell clonality and immune-phenotyping. The more common benign type 1 accounts for $85 \%$ of all cases of RCD [3,4], and has normal appearing intraepithelial lymphocytes, while type

Manuscript submitted March 06, 2017, accepted March 29, 2017

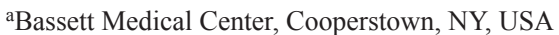

bDow University of Health and Sciences, Karachi, Pakistan

${ }^{\mathrm{c} C o r r e s p o n d i n g ~ A u t h o r: ~ U m a i r ~ I q b a l, ~ B a s s e t t ~ M e d i c a l ~ C e n t e r, ~ C o o p e r s t o w n, ~}$

NY, USA. Email: umair.iqbal@bassett.org
2 has an aberrant/premalignant population of intraepithelial lymphocyte and can progress to enteropathy-associated T-cell lymphoma $[3,5,6]$. Differentiation between type I and type II refractory $\mathrm{CD}$ is important for management as well as prognosis [5]. Gluten-free diet is the cornerstone of treatment along with immunosuppression and nutritional support. Mild immunosuppression is usually enough for the type I while type II requires strong immunosuppression. However, due to limited number of cases reported in the literature, treatment of RCD has remained a challenge for clinicians.

\section{Case Report}

A 75-year-old female with history of hypertension presented with 3 months history of non-bloody diarrhea and significant weight loss. No recent travel or antibiotic use was reported. Besides mild anemia, serum and stool studies were unremarkable. Colonoscopy was insignificant. EGD showed mild non-erosive erythema affecting gastric body and antrum with duodenum showing lack of visible villi (Figs. 1 and 2). Small bowel biopsy showed classical flattening of duodenal mucosa with total lack of villi and increased chronic inflammatory cells in the lamina propria and patchy surface intraepithelial lymphocytosis (Fig. 3). Serological tests showed elevated levels of

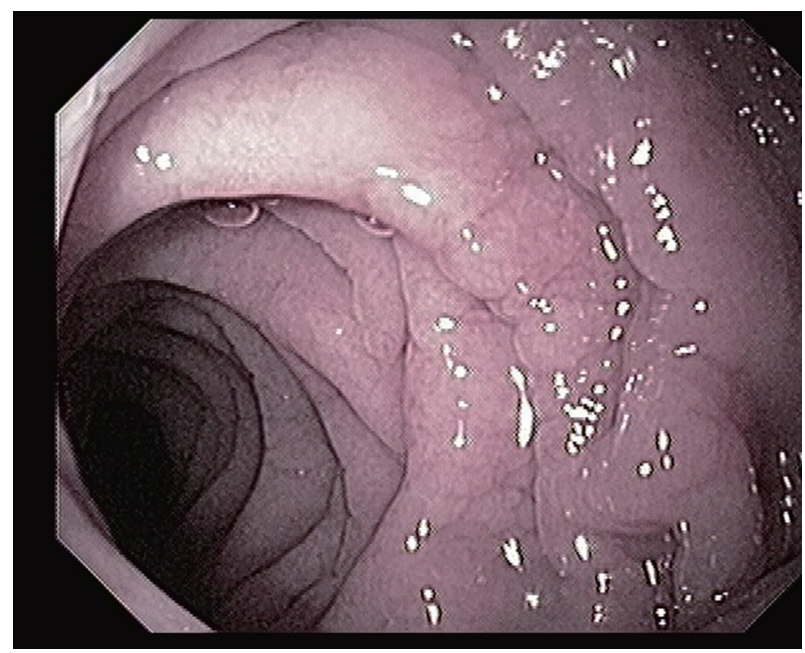

Figure 1. Duodenum showing lack of visible villi. 


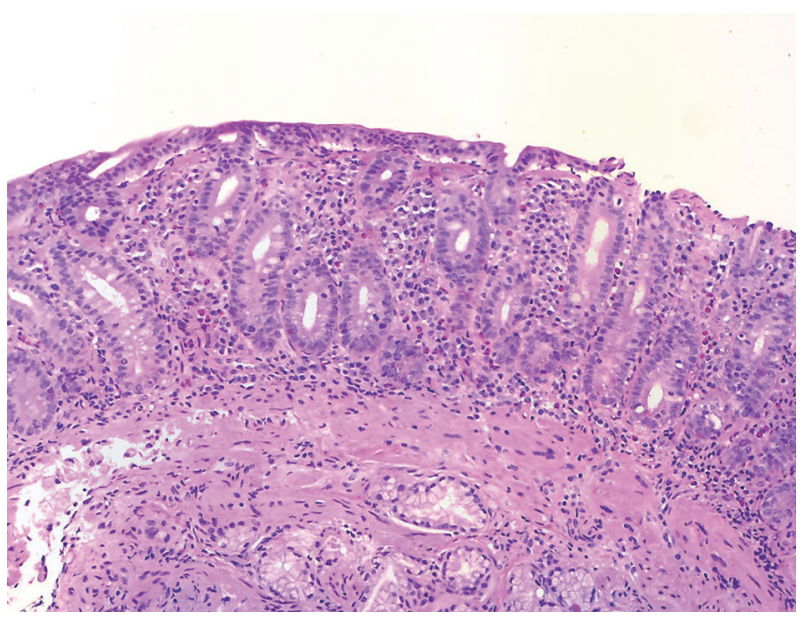

Figure 2. Duodenum showing complete lack of villi.

tissue transglutaminase antibodies and positive anti-endomysial antibodies. Her symptoms improved with strict gluten-free diet. Repeat EGD showed remarkable improvement in small bowel mucosal and histologic pattern. Repeat serological tests with anti-endomysial antibody were also negative. Despite strict gluten-free diet, 3 years later the patient presented with a relapse. EGD was done to evaluate the cause of relapse which showed complete atrophy of small bowel villi. She was started on high doses of steroids, but her symptoms persisted. Azathioprine was added and marked improvement in GI symptoms. Repeat EGD and biopsy also showed small bowel morphology and histological pattern. Steroids were gradually tapered off, but azathioprine was continued. She is now in remission for the past 7 years on azathioprine.

\section{Discussion}

RCD is defined as villous atrophy mimicking $C D$, not responding to at least $6-12$ months of a strict gluten-free diet and is not attributable to other causes of villous atrophy like tropical sprue, Whipple's disease, giardiasis, HIV, etc. $[4,7,8]$. Primary RCD is defined as a total lack of response, whereas secondary refers to a recurrence of sign/symptoms or laboratory abnormalities after initial response to a gluten-free diet [6].

Although the cause of RCD has not been fully elicited, unintentional or deliberate gluten ingestion seems to be the commonest cause of apparent unresponsiveness to GFD because a strict gluten-free diet is very difficult to follow due to the environmental ubiquity $[1,5,9,10]$. Signs and symptoms like abdominal bloating, fatigue, constipation, and osteoporosis are non-specific but persistent diarrhea and unintentional weight loss despite strict adherence to gluten-free diet in patients with $\mathrm{CD}$ should trigger consideration of RCD. As mentioned earlier classification of RCD into type I and II is important and can be done on histologic evaluation of small bowel. RCD I does not have atypical lymphocytes and has normal expression of T-cell receptors [3-5], CD3 and CD8, while RCD II has loss of expression of T-cell receptors, CD3 and CD8. RCD type II carries a poor prognosis due to risk of progression to enterop-

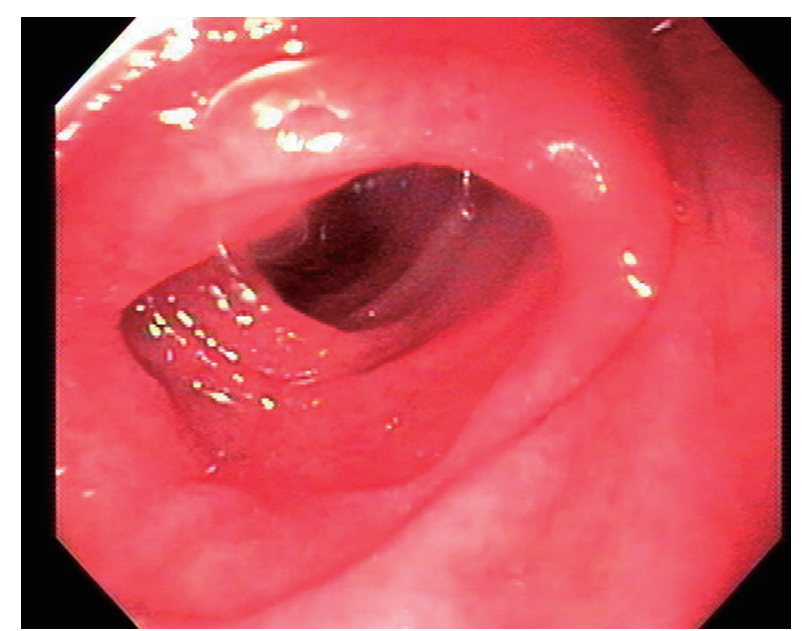

Figure 3. Histopathology showing classical flattening of duodenal mucosa with total lack of villi and increased chronic inflammatory cells in the lamina propria.

athy-associated T-cell lymphoma with a 5-year survival rate of approximately $50 \%$ compared with approximately $90 \%$ for RCD type I [4].

Current recommendations from American College of Gastroenterology regarding management of RCD involve differentiation between subtypes prior to any treatment given. Medications should be considered as an adjunct to gluten-free diet with close monitoring of the patient and aggressive nutritional support [11]. Oral and parental steroids with or without immunosuppressants are the mainstream options. Some patients respond with a successful outcome while others require very high doses to maintain remission, and they may have a relapse when a reduction of the dose is initiated $[12,13]$. Among corticosteroids budesonide is as effective as prednisolone in inducing and sustaining remission in type I and can be used in type II $[5,13]$. Among immunosuppressive agents, cyclophosphamide, cyclosporine, tioguanine, methotrexate, 5-aminosalicylic acid (5-ASA), azathioprine and infliximab have been reported to be useful in some patients but not in others $[3,8,12$, 13]. Data on azathioprine use are heterogenous. Maurino et al [12] found it effective even when high-dose steroids failed to respond. However, Goerres et al [14] found azathioprine noneffective when used with prednisolone in patients with RCD type II.

Azathioprine is steroid sparing and can be used to achieve clinical remission. It has also been reported to be effective when steroids fail [12]. The basis for using azathioprine in refractory sprue is based on its interference in the purine synthesis that may lead to DNA damage and hence preventing the clonal expansion of both B and T lymphocytes. However, azathioprine produces toxicity by affecting rapidly growing cells of the body, including GI mucosa and bone marrow causing leukopenia with increased risk of infections. It is also hepatotoxic [12]. More recently chemotherapy with cladribine with or without autologous stem cell transplantation [3] and fecal microbiota transfer [14] has also been reported to be useful.

In summary, management of RCD remains a challenge, especially those not responding to conventional steroid therapy. 
Azathioprine in our case was found to be an effective treatment and could be considered in such patients to achieve remission, but further studies are necessary to enroll more patients for this type treatment to get a definite conclusion.

\section{Consent}

Witnessed informed consent taken from the patient to publish case report with images.

\section{Financial Support}

None.

\section{References}

1. Leffler DA, Edwards George JB, Dennis M, Cook EF, Schuppan D, Kelly CP. A prospective comparative study of five measures of gluten-free diet adherence in adults with coeliac disease. Aliment Pharmacol Ther. 2007;26(9):1227-1235.

2. West J. Celiac disease and its complications: a time traveller's perspective. Gastroenterology. 2009;136(1):32-34.

3. Refractory Celiac Disease - NORD (National Organization for Rare Disorders). (n.d.). Retrieved November 29, 2016, from https://rarediseases.org/rare-diseases/refractory-celiac-disease/.

4. Roshan B, Leffler DA, Jamma S, Dennis M, Sheth S, Falchuk K, Najarian R, et al. The incidence and clinical spectrum of refractory celiac disease in a north american referral center. Am J Gastroenterol. 2011;106(5):923-928.

5. Abdallah H, Leffler D, Dennis M, Kelly CP. Refractory celiac disease. Curr Gastroenterol Rep. 2007;9(5):401405 .
6. Cellier C, Delabesse E, Helmer C, Patey N, Matuchansky C, Jabri B, Macintyre E, et al. Refractory sprue, coeliac disease, and enteropathy-associated T-cell lymphoma. French Coeliac Disease Study Group. Lancet. 2000;356(9225):203-208.

7. Tack GJ, van Asseldonk DP, van Wanrooij RL, van Bodegraven AA, Mulder CJ. Tioguanine in the treatment of refractory coeliac disease - a single centre experience. Aliment Pharmacol Ther. 2012;36(3):274-281.

8. Vahedi K, Mascart F, Mary JY, Laberenne JE, Bouhnik Y, Morin MC, Ocmant A, et al. Reliability of antitransglutaminase antibodies as predictors of gluten-free diet compliance in adult celiac disease. Am J Gastroenterol. 2003;98(5):1079-1087.

9. Abdulkarim AS, Burgart LJ, See J, Murray JA. Etiology of nonresponsive celiac disease: results of a systematic approach. Am J Gastroenterol. 2002;97(8):2016-2021.

10. Rubio-Tapia A, Hill ID, Kelly CP, Calderwood AH, Murray JA. ACG clinical guidelines: diagnosis and management of celiac disease. Am J Gastroenterol. 2013;108(5):656-676; quiz 677.

11. Maurino E, Niveloni S, Chernavsky A, Pedreira S, Mazure R, Vazquez H, Reyes H, et al. Azathioprine in refractory sprue: results from a prospective, open-label study. Am J Gastroenterol. 2002;97(10):2595-2602.

12. Daum S, Ipczynski R, Heine B, Schulzke JD, Zeitz M, Ullrich R. Therapy with budesonide in patients with refractory sprue. Digestion. 2006;73(1):60-68.

13. Goerres MS, Meijer JW, Wahab PJ, Kerckhaert JA, Groenen PJ, Van Krieken JH, Mulder CJ. Azathioprine and prednisone combination therapy in refractory coeliac disease. Aliment Pharmacol Ther. 2003;18(5):487-494.

14. van Beurden $Y H$, van Gils T, van Gils NA, Kassam Z, Mulder CJ, Aparicio-Pages N. Serendipity in Refractory Celiac Disease: Full Recovery of Duodenal Villi and Clinical Symptoms after Fecal Microbiota Transfer. J Gastrointestin Liver Dis. 2016;25(3):385-388. 